\title{
PEMETAAN LOKASI LKP DAN BIMBINGAN BELAJAR DI KABUPATEN ASAHAN BERBASIS WEBGIS
}

\author{
Romy Aulia \\ Program Studi Sistem Informasi, \\ Sekolah Tinggi Manajemen dan Informatika Royal Kisaran \\ Jln.Prof.H.M.Yamin No.173 Telp.0623 -41079, Kisaran, Kab Asahan, Prov.Sumatera Utara-Indonesia \\ romysinggalang@gmail.com
}

\begin{abstract}
There are many ways that the government can do to improve the level of education and skills of the community, for example by giving permission to establish a LKP (Lembaga Keterampilan Pelatihan) and a place for Tutoring (Bimbel). In Asahan District, there are several LKP and Bimbel locations that already have licenses from the Asahan District Education Office. However, data and information about the location of the LKP and the Bimbel are still manual. Along with the development of technology, the name of the Geographical Information System appears that can store data and show information about the location of a place. For this reason, mapping of LKP and Bimbel locations in Kab. Asahan is based on webgis in order to be able to assist in data collection and provide information to the community regarding LKP and Bimbel locations in Asahan.
\end{abstract}

Keywords - Geographical Information System, Webgis, LKP, Bimbel.

Abstract - Banyak cara yang bisa dilakukan pemerintah untuk bisa meningkatkan taraf pendidikan dan keterampilan masyarakat, contohnya adalah dengan memberikan izin untuk pendirian LKP (Lembaga Keterampilan Pelatihan) dan tempat untuk Bimbingan Belajar (bimbel). Di Kabupaten Asahan, terdapat beberapa LKP dan tempat Bimbel yang sudah mempunyai izin dari Dinas Pendidikan Kabupaten Asahan. Namun, data dan informasi mengenai lokasi LKP dan Bimbelnya masih bersifat manual. Seiring dengan perkembanagan teknologi, munculah yang namanya Sistem Informasi Geografi yang bisa menyimpan data dan menunjukan informasi mengenai lokasi suatu tempat. Untuk itu dibuatlah pemetaan lokasi LKP dan Bimbel di Kab. Asahan berbasis webgis agar dapat membantu pendataan dan memberikan informasi kepada masyarakat terkait lokasi LKP dan Bimbel yang ada di Kab, Asahan.

Kata kunci - Sistem Informasi Geografis, Webgis, LKP, Bimbel.

\section{PENDAHULUAN}

Kabupaten Asahan adalah salah satu kabupaten di Provinsi Sumatera Utara dengan penduduk lebih kurang 712.684 jiwa yang terdata pada tahun 2016[1]. Beberapa tahun terakhir kabupaten Asahan menunjukan perkembangan yang semakin pesat, ditandai dengan semakin menjamurnya tempat kuliner, sarana hiburan dan tumbuhnya beberapa Lembaga Keterampilan dan Pelatihan (LKP) dan Bimbingan Belajar (Bimbel) yang tujuan untuk meningkatkan ilmu pengetahuan dan keterampilan yang dimiliki masyarakat, namun data dan informasi lokasi LKP dan Bimbel ini masih dikelola secara manual.

Bimbingan belajar adalah suatu bentuk kegiatan dalam proses belajar yang cepat, dilakukan oleh seseorang yang telah memiliki kemampuan lebih dalam banyak hal untuk diberikan kepada orang lain yang mana bertujuan agar orang lain dapat menemukan pengetahuan baru yang belum dimilikinya serta dapat diterapkan dalam kehidupannya[2]. Pada saat sekarang ini lembaga bimbingan belajar sudah banyak tersebar diberbagai daerah di Kabupaten Asahan terutama di kota Kisaran.

Dinas pendidikan Kabupaten Asahan merupakan suatu instansi pemerintah yang bertanggung jawab tentang semua hal yang berkaitan dengan pendidikan di wilayahnya. Melalui kantor dinas pendidikan ini, pemerintah daerah bidang pendidikan melakukan tugas pada wilayah kerjanya. Tugas tersebut mencakup pembantuan urusan pendudukan, pengawasan, penyusunan program pendidikan daerahnya, menyusun strategi, perumusan kebijakan pendidikan, hingga memberikan layanan umum dalam hal pendidikan. Dinas pendidikan ini juga menjadi pembina dan pemberi izin sekolah dari taman kanak-kanak, sekolah dasar, sekolah menengah pertama, sekolah menengah atas, dan lembaga bimbingan belajar non formal.[3]

Adapun Lembaga Keterampilan Pelatihan serta Bimbingan Belajar di kabupaten Asahan yang terdaftar dan terdata oleh Dinas Pendidikan Kabupaten Asahan adalah sebagai berikut : 
Tabel 1. Data LKP

\begin{tabular}{|c|c|c|}
\hline Nama & Alamat & $\begin{array}{c}\text { Jenis } \\
\text { Kursus }\end{array}$ \\
\hline $\begin{array}{l}\text { LKP } \\
\text { Intelcom } \\
\text { Global } \\
\text { Indo }\end{array}$ & $\begin{array}{lr}\text { Jl. } & \text { Hos. } \\
\text { Cokroaminoto } & \text { No. } \\
\text { 127 Kisaran. } & \end{array}$ & Komputer \\
\hline $\begin{array}{l}\text { LKP } \\
\text { Mahas } \\
\text { Com }\end{array}$ & $\begin{array}{ll}\text { Jl. Ikan } & \text { Patin Gg. } \\
\text { P2KP } & \text { Sidomukti } \\
\text { Asahan } & \end{array}$ & Komputer. \\
\hline $\begin{array}{l}\text { LKP } \\
\text { Triple AI }\end{array}$ & $\begin{array}{l}\text { Jl. Sawo LK.III Kel. } \\
\text { Sentang Kec. Kisaran } \\
\text { Timur. }\end{array}$ & Komputer. \\
\hline $\begin{array}{l}\text { English } \\
\text { Study } \\
\text { Centre }\end{array}$ & $\begin{array}{l}\text { Jl. Hamka No. } 15 \text { Lk. } \\
\text { II }\end{array}$ & $\begin{array}{l}\text { Bahasa } \\
\text { Inggris. }\end{array}$ \\
\hline $\begin{array}{l}\text { LKP One } \\
\text { Stop } \\
\text { Education } \\
\text { Center }\end{array}$ & $\begin{array}{l}\text { Jl. Dr. } \text { Cipto No.7 } \\
\text { LK.IV Kec. Kisaran } \\
\text { Barat }\end{array}$ & $\begin{array}{l}\text { Bahasa } \\
\text { Inggris. }\end{array}$ \\
\hline $\begin{array}{l}\text { LKP } \\
\text { Adithiya } \\
\text { Education } \\
\text { Center }\end{array}$ & $\begin{array}{lr}\text { Jl. Wira } & \text { Karya } \\
\text { No.15/16C } & \text { Kec. } \\
\text { Kisaran Barat } & \end{array}$ & $\begin{array}{l}\text { Bahasa } \\
\text { Inggris dan } \\
\text { Matematika. }\end{array}$ \\
\hline $\begin{array}{l}\text { LKP Baby } \\
\text { Com } \\
\text { Asahan }\end{array}$ & $\begin{array}{ll}\text { Jl. Rambe LK.V } \\
\text { Kedai Ledang Kec. } \\
\text { Kisaran Timur }\end{array}$ & Komputer. \\
\hline $\begin{array}{l}\text { LKP } \\
\text { Farhan } \\
\text { Computer } \\
\text { Center }\end{array}$ & $\begin{array}{l}\text { Jl. K.H. Agus Salim } \\
\text { Gg. Citra No. } 20 \text { Kec. } \\
\text { Kisaran Timur }\end{array}$ & Komputer. \\
\hline $\begin{array}{l}\text { LKP Smart } \\
\text { Study } \\
\text { Center }\end{array}$ & $\begin{array}{l}\text { Jl. Setia Budi } \text { Gang } \\
\text { Kelapa No.22 Kec. } \\
\text { Kisaran Timur }\end{array}$ & Komputer. \\
\hline $\begin{array}{ll}\text { LKP } & \text { Star } \\
\text { Com } & \end{array}$ & $\begin{array}{ll}\text { Jl. Melur } & \text { No.26 } \\
\text { Kisaran Naga } & \text { Kec. } \\
\text { Kisaran Timur } & \\
\end{array}$ & Komputer. \\
\hline $\begin{array}{l}\text { LKP Sang } \\
\text { Bintang }\end{array}$ & $\begin{array}{l}\text { Jl. Bakti No.19 Kec. } \\
\text { Kisaran Timur }\end{array}$ & $\begin{array}{l}\text { Bahasa } \\
\text { Inggris, } \\
\text { Pendidikan } \\
\text { dan } \\
\text { Pelatihan. }\end{array}$ \\
\hline Primagama & $\begin{array}{ll}\text { Jl. Pelita } & \text { No.2 } \\
\text { Kisaran } & \\
\end{array}$ & $\begin{array}{l}\text { Bimbingan } \\
\text { Belajar. }\end{array}$ \\
\hline $\begin{array}{l}\text { Asahan } \\
\text { Cerdas }\end{array}$ & $\begin{array}{l}\text { Jl. Setia Budi No.36 } \\
\text { Selawan }\end{array}$ & $\begin{array}{l}\text { Bimbingan } \\
\text { Belajar. }\end{array}$ \\
\hline $\begin{array}{l}\text { Adzkia } \\
\text { Stan }\end{array}$ & $\begin{array}{lr}\text { Jl.Ahmad } & \text { Yani } \\
\text { Komplek } & \text { Graha } \\
\text { Asahan Kec. } & \text { Kisaran } \\
\text { Barat } & \end{array}$ & $\begin{array}{l}\text { Bimbingan } \\
\text { Belajar. }\end{array}$ \\
\hline $\begin{array}{l}\text { Ganesha } \\
\text { Operation }\end{array}$ & $\begin{array}{l}\text { Jl. Sisingamangaraja } \\
\text { No. } 318 \text { Kisaran. }\end{array}$ & $\begin{array}{l}\text { Bimbingan } \\
\text { Belajar. }\end{array}$ \\
\hline
\end{tabular}

Basis data adalah sekumpulan data yang saling berhubungan secara logis dan terorganisir dengan baik. Kumpulan data tersebut yang saling berhubungan yang disimpan secara bersama sedemikian rupa dan tanpa pengulangan (redudansi) yang tidak perlu, untuk memenuhi berbagai kebutuhan. Kumpulan file/tabel/arsip yang saling berhubungan yang disimpan dalam media penyimpanan elektronik[4]

Sistem Informasi Geografis (SIG) atau Geographic Information System (GIS) adalah sebuah sistem yang didesain untuk menangkap, menyimpan, memanipulasi, menganalisa, mengatur dan menampilkan seluruh jenis data geografis.[5]. Dengan demikian SIG merupakan sistem komputer yang memiliki empat kemampuan berikut dalam menangani data yang bereferensi geografi: (a) masukan, (b) manajemen data (penyimpanan dan pemanggilan data), (c) analisis dan manipulasi data, (d) keluaran. [6]

Untuk itu diharapkan, GIS atau SIG ini dapat membantu pemerintah, khususnya Dinas Pendidikan Kabupaten Asahan untuk mendata lokasi LKP dan Bimbel yang ada di Asahan serta memudahkan masyarakat mencari informasi mengenai LKP dan Bimbel tersebut.

\section{METODE PENELITIAN}

Metode penelitian yang digunakan dalam penelitian ini adalah metode penelitian kuantitatif yang lebih menekankan pada aspek pengukuran secara obyek terhadap fenomena pendidikan, dengan tujuan mengetahui jumlah dan lokasi objek.

1. Wawancara

Yaitu teknik pengumpulan data dengan cara tanya jawab secara langsung dengan pegawai dinas pendidikan kab.Asahan.

2. Pengamatan

Teknik pengumpulan data dengan melakukan pengamatan atau datang langsung ke lokasi penelitian

3. Dokumentasi

Dokumentasi yaitu tahapan pembuatan laporan akan data-data yang telah diperoleh setelah melakukan penelitian di lapangan.

4. Perancangan Sistem

Perancangan system ini dibantu dengan UML yang digunakan untuk pembuatan diagram. UML nya antara lain usecase diagram, activity diagram, sequence diagram.

5. Implementasi dan Pengujian Sistem

Implementasi adalah penerapan system yang telah dirancang sebelumnya dengan tujuan untuk menentukan apakah layak untuk diterapkan atau tidak layak untuk diterapkan. Sebelum digunakan oleh user system ini harus dilakukan pengujian terlebih dahulu untuk mengurangi resiko kesalahan fatal sewaktu digunakan oleh user yang mengakses webgis ini. 


\section{HASIL DAN PEMBAHASAN}

A. Pengembangan Sistem Webgis

1. Usecase Diagram

Diagram ini menggambarkan hubungan satu atau lebih actor dengan system informasi geografis yang akan dibuat. Use case harus mampu mengambarkan urutan aktor yang menghasilkan nilai terukur[7]. Usecase digunakan untuk mengetahui fungsi apa saja yang ada di dalam sebuah sistem dan siapa saja yang berhak menggunakan fungsi-fungsi tersebut[8]. Adapun bentuk gambar usecase diagramnya adalah sebagai berikut :

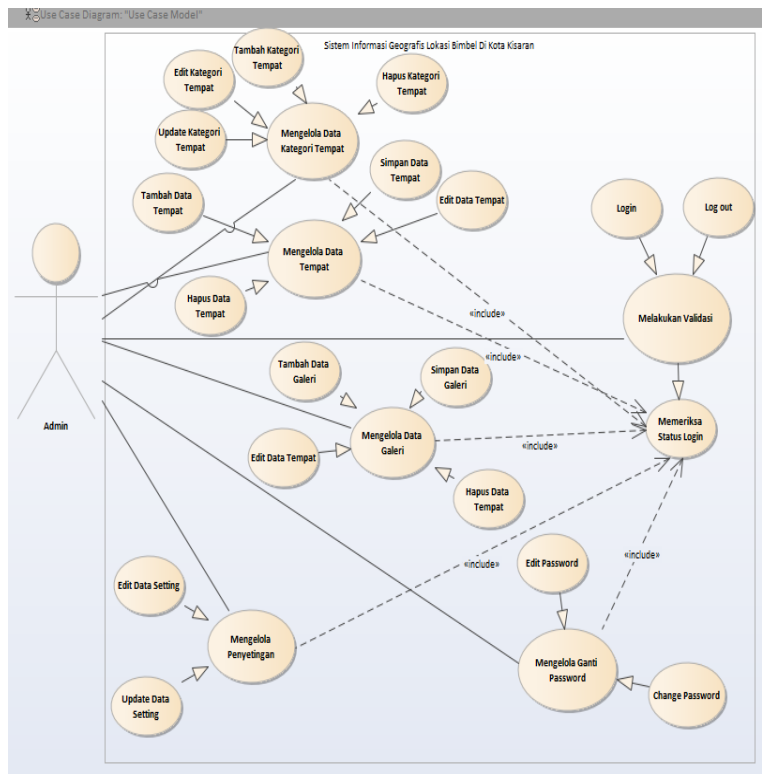

Gambar 1. Use Case Diagram Admin

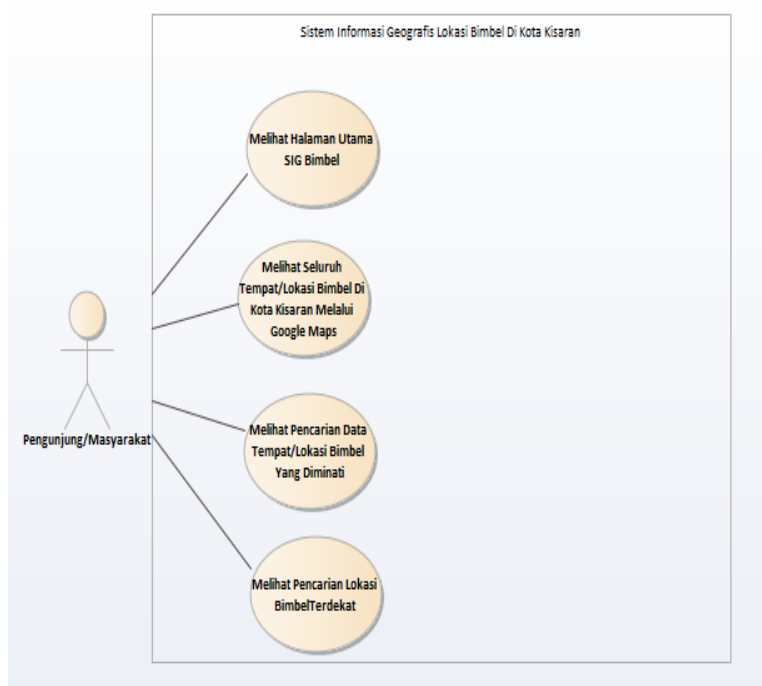

Gambar 2. Use Case Diagram User/masyarakat
Aktor pada system ini didefinisikan menjadi dua actor yaitu admin dan user (masyarakat / pengunjung). Admin dapat login ke sistem dan memiliki hak akses untuk melakukan operasi pengolahan data-data yang berkaitan mengenai informasi data LKP dan Bimbel yang ada di Kab.Asahan. Sementara user / masyarakat orang yang dapat melihat dan membaca informasiinformasi yang disediakan sistem mengenai persebaran lokasi LKP dan Bimbingan Belajar yang ada di Kabupaten Asahan.

\section{Activity Diagram}

Diagram activity adalah aktifitas-aktifitas, objek, state, transisi state dan event. Dengan kata lain kegiatan diagram alur kerja menggambarkan perilaku sistem untuk aktivitas.[7]

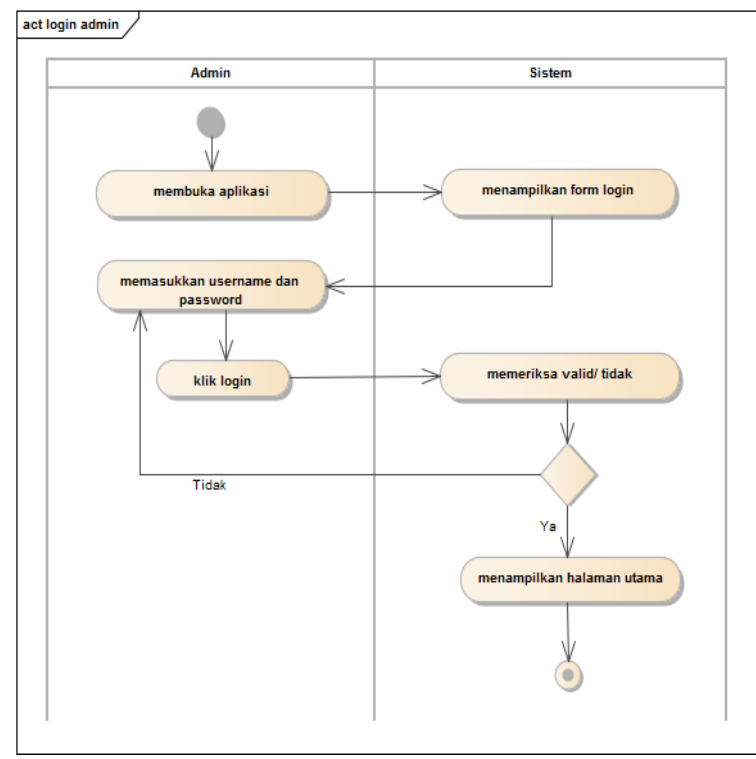

Gambar 3. Activity Diagram Login Admin

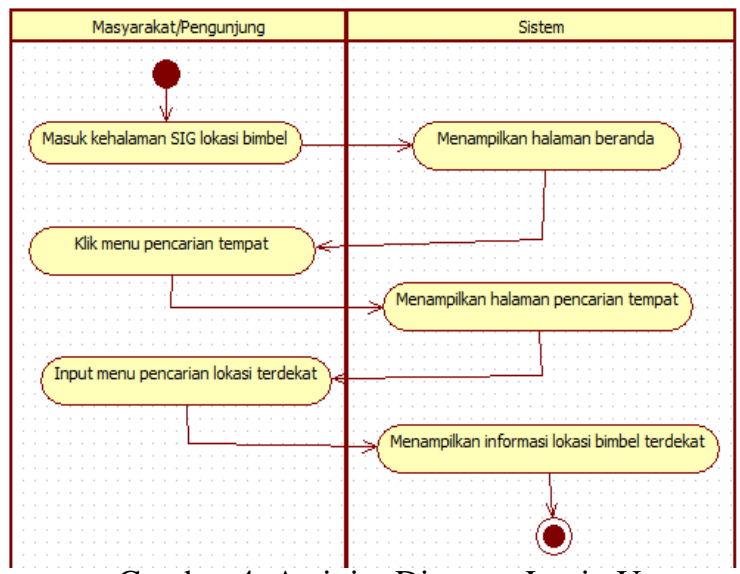

Gambar 4. Activity Diagram Login User

\section{Sequence Diagram}


Sequence Diagram dibuat agar dapat mempermudah melihat interaksi antar aktor, Sistem dan database secara dinamis.[9]. Interaksi dari objek yang disusun dalam suatu urutan waktu / kejadian tertentu dalam suatu proses, dapat digambarkan dengan sequence diagram.[10]

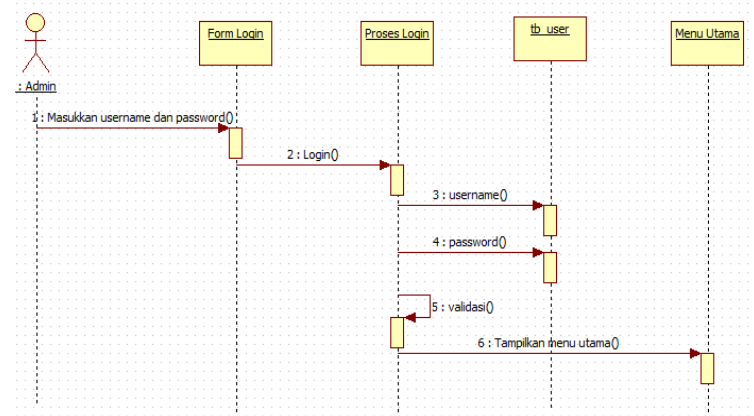

Gambar 5. Sequence Diagram Login Admin

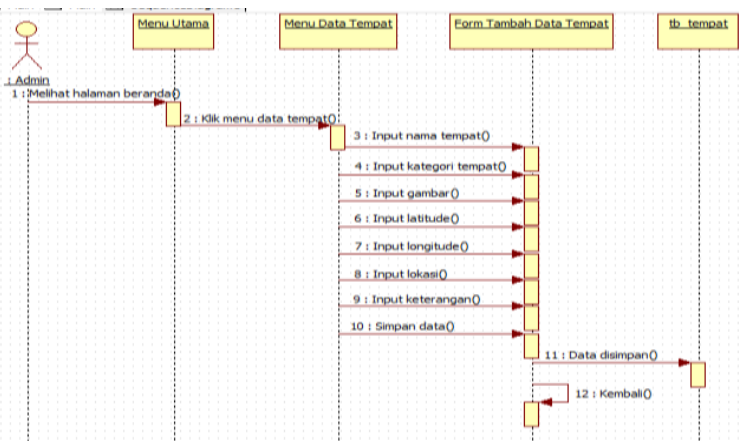

Gambar 6. Sequence Diagram Login Admin

B. Implementasi Dan Hasil Webgis

Implementasi dapat dilihat di beberapa gambar berikut ini :

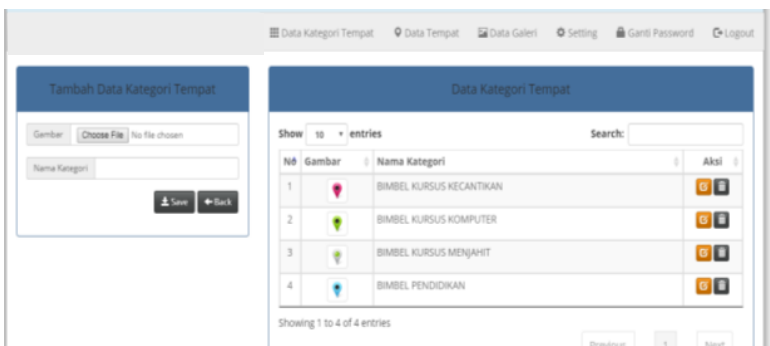

Gambar 7. Data Kategori

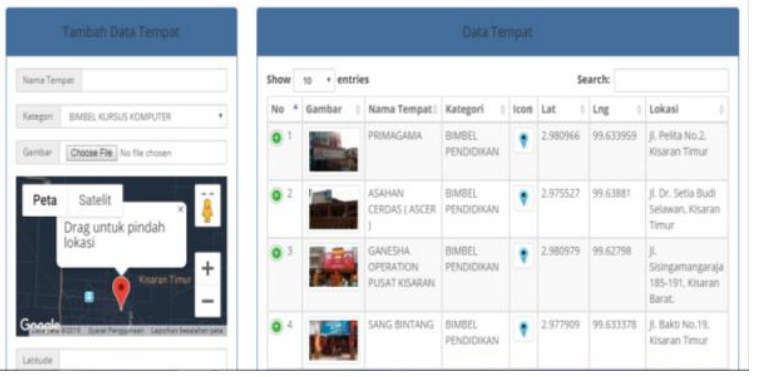

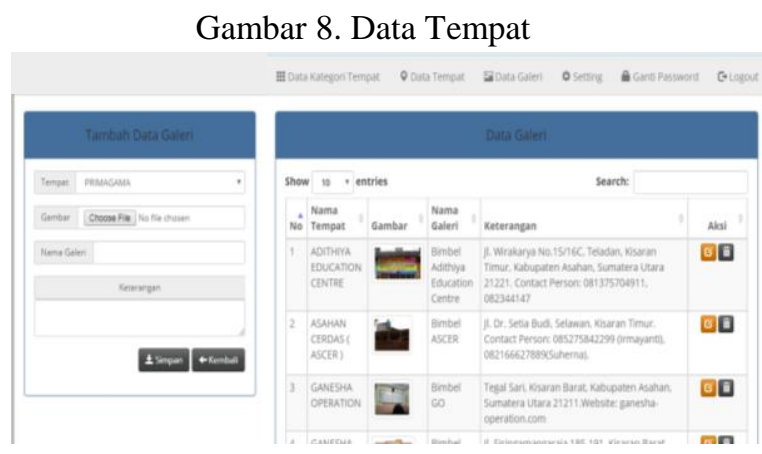

Gambar 9. Data Galeri

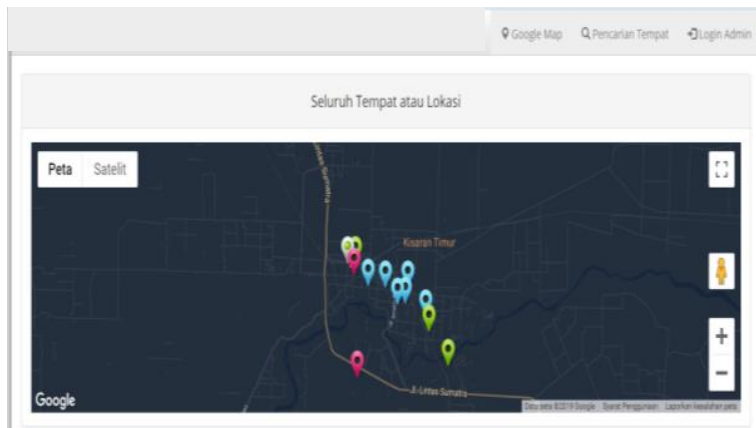

Gambar 10. Lokasi LKP

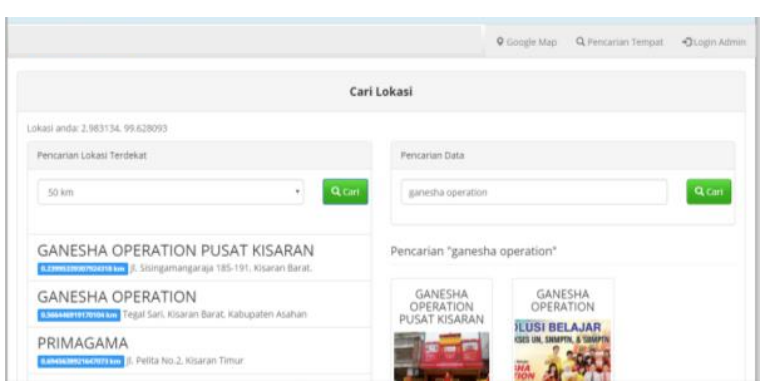

Gambar 11. Pencarian Lokasi

\section{KESIMPULAN}

Berdasarkan penelitian, implementasi dan pengujian, maka dapat diambil kesimpulan sebagai berikut :

1. Pemetaan lokasi LKP dan bimbel di Kab.Asahan berbasis webgis ini mampu menghimpun seluruh data lokasi LKP dan bimbel yang ada di daerah Kab.Asahan.

2. Informasi yang dihasilkan dan ditampilkan dapat dilihat dan digunakan oleh masyarakat luas sebagai penambah informasi mereka mengenai LKP dan bimbel apa saja yang ada di Kab.Asahan lengkap dengan lokasi dan fasilitas yang disediakan.

\section{DAFTAR PUSTAKA}

[1] S. Royal and A. Royal, "Seminar Nasional Royal ( SENAR ) 2018 IMPLEMENTASI METODE LEAST SQUARE UNTUK 
PERAMALAN .," vol. 9986, no. September, 2018.

[2] R. El Fiah and A. P. Purbaya, "Penerapan Bimbingan Belajar dalam Meningkatkan Hasil Belajar Peserta Didik di SMP Negeri 12 Kota Bandar Lampung Tahun Pelajaran 2015/2016," KONSELI J. Bimbing. dan Konseling, vol. 3, no. 2, pp. 161-174, 2016.

[3] P. Daerah and K. Ibukota, "Dinas pendidikan," no. 3, pp. 1-7, 2016.

[4] K. M. Wibowo, K. Indra, and J. Jumadi, "Sistem Informasi Geografis (SIG) Menentukan Lokasi Pertambangan Batu Bara di Provinsi Bengkulu Berbasis Website," J. Media Infotama, vol. 11, no. 1, pp. 51-60, 2015.

[5] J. Siswanto and M. Jazman, "RANCANG BANGUN WEBGIS PEMETAAN LOKASI PANTI SOSIAL MENGGUNAKAN PMAPPER (Studi Kasus: Dinas Sosial dan Pemakaman Kota Pekanbaru)," J. Rekayasa dan Manaj. Sist. Inf., vol. 2, no. 2, pp. 137143, 2016.

[6] S. I. Geografi, "Pengembangan Database Spasial untuk Pembuatan Aplikasi Berbasis GIS," vol. X, no. 3, pp. 133-142, 2005.

[7] Suendri, "Implementasi Diagram UML (Unified Modelling Language) Pada Perancangan Sistem Informasi Remunerasi Dosen Dengan Database Oracle (Studi Kasus: UIN Sumatera Utara Medan)," J. Ilmu Komput. dan Inform., vol. 3, no. 1, pp. 1-9, 2018.

[8] Yunahar Heriyanto, "Perancangan Sistem Informasi Rental Mobil Berbasis Web Pada PT.APM Rent Car," J. Intra-Tech, vol. 2, no. 2, pp. 64-77, 2018.

[9] S. Sutejo, "Pemodelan UML Sistem Informasi Geografis Pasar Tradisional Kota Pekanbaru," Digit. Zo. J. Teknol. Inf. dan Komun., vol. 7 , no. 2, pp. 89-99, 2016, doi: 10.31849/digitalzone.v7i2.600.

[10] R. Novita and N. Sari, "Sistem Informasi Penjualan Pupuk Berbasis E-Commerce," Teknoif, vol. 3, no. 2, pp. 1-6, 2015. 